\title{
BUILDING SPATIAL DATABASE FOR CUTTACK MUNICIPAL CORPORATION: A GEOSPATIAL TECHNOLOGICAL APPROACH
}

\author{
Pritirekha Daspattanayak $^{1}$, Prabhu Prasad Das ${ }^{2}$ \\ ${ }^{1,2}$ Dept. of Applied Geography, Ravenshaw University, Cuttack, Odisha -753003 \\ pritirekha1962@gmail.com,prabhuprasaddas@gmail.com
}

\begin{abstract}
Decentralized governance necessitates participatory approach which is crucial for realizing sustainable development. Accordingly, the concerned government as well as non-government agencies assume responsibility to plan, execute, manage and monitor social welfare schemes in a coordinated manner. This in turn, relies on integrated information in the form of database which plays a vital role in the process of decision making. Despite significant improvements made in the field of database creation and management, problems of availability and organization of accurate data in the country continue to persist. In this context, the present study is taken up for building a reliable and accurate geo-database for Cuttack Municipal Corporation, Odisha. The database thus created will enable information flow for planning and monitoring of various government schemes. The study involves acquisition and integration of spatial and non-spatial data derived from multiple sources. More often than not, data from these sources suffer from various types of errors embedded in it. Lack of availability of cutting edge technologies within government enterprises as well as absence of appropriate manpower with specialized expertise are the underlying reasons of errors in existing databases of Cuttack Municipal Corporation. The present study proposes a methodological framework towards removal of these errors in spatial information. The study is based on geospatial technologies of Remote Sensing, Geographic Information System and Global Positioning System in generating a desired accurate and common geo-database for planning and implementation of social welfare schemes. While Global Positioning System and Remote Sensing imageries can help enhance the positional accuracies of spatial entities, data management, analysis and visualization capabilities of Geographic Information System can help build the standard geo-database which can be shared by policy makers for better implementation of the schemes.
\end{abstract}

Key words: Geospatial, Database, Remote Sensing, GIS, GPS

\section{INTRODUCTION}

The socio-economic condition in India has undergone a significant transformation in the wake of rapid industrialisation and urbanisation in recent times. Urban centres in the country are said to be the engines of economic growth. However, existence of common geo-database for these centres of growth is still very scarce. Provision and maintenance of basic services and infrastructure to the common dwellers assume prime significance in planning processes for sustainable growth and development of the country. The urban centres of the country and more so in Odisha, are facing acute space scarcity towards further development. In the wake of exponential population growth, these urban centres are expanding in an obvious manner beyond their limits, a process often explained as 'urban sprawl'. This haphazard and chaotic spatial expansion needs appropriate supervision and administration. In order to achieve and maintain sustainable growth of these cities, the need of the hour is to up-date, coordinate and integrate database having both spatial and non-spatial information for sharing between various government and non-government agencies. This will form the basis for proper planning, execution, monitoring and policy making decisions. In other words, the existence of a common spatial database for the Urban Local Bodies (ULBs) becomes a necessity rather than an option. Geospatial or geocoded database which includes explicit geographical positioning of particular attributes becomes an integral input of planning strategies (Bedard, 1999). In this context, geospatial technologies of Remote Sensing (RS), Geographic Information System (GIS) and Global Positioning System (GPS) assume utmost significance in building the geospatial database for these targeted spatial entities.

While the technology of remote sensing has brought a boon in collecting enormous volume of unbiased spatial data within determinable accuracy and precision, GIS gives the power of managing, analyzing and displaying these collected data in a very efficient manner (Batini, et al 1992; Sheldon, 1993; Elmasri and Navathe, 1989). Spatial geographic positional accuracy is added to the collected data with the help of GPS. Moreover, with the advancement of the technology it is now possible to make all these spatial information available to not only decision makers located at different places but also to the common users on the web platform of internet (Abdelmoty et al, 1993; Abel, 1989; Abdelmoty 1993). 


\section{THE PRESENT STUDY}

In context of the above, the present study endeavours to build a methodological framework for the creation of geospatial database for the Cuttack Municipal Corporation.

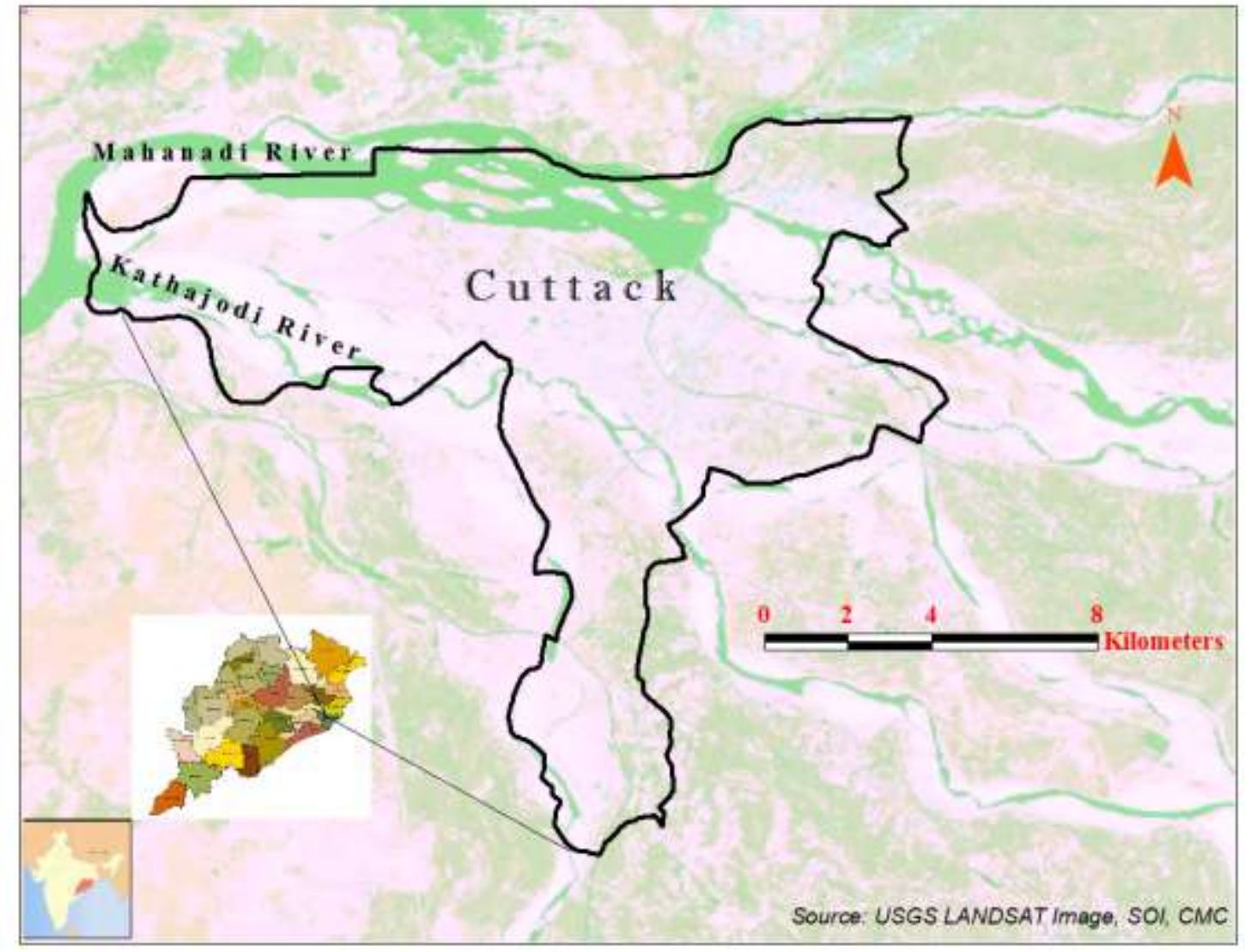

Fig-1: Location of the study area

The study forms part of a project funded by the Department of Science and Technology, DST, Government of India. For the study secondary spatial information related to the city of Cuttack has been acquired from Cuttack Municipal Corporation (CMC) and the Survey of India (SOI).

\section{OBJECTIVE}

The cardinal objective of the study is to appreciate the potential efficacy of geospatial technology including RS, GIS \& GPS in creating a spatial database for decentralized governance of a city and its suburban areas taking Cuttack as an example. The chief focus, thus, is on methodological framework towards building a geospatial database for urbanlocal bodies.

\section{STUDY AREA}

Cuttack is the oldest city of the state of Odisha. One of the most densely populated urban centres in the country, Cuttack is an important centre of commercial activities. and along with its peripheral small and large scale industries constitute one of the most developed urbanized centres of the country. The city is subdivided in to 59 wards that come under the jurisdiction of CMC. The spatial extent of the study area is approximately from $20^{\circ} 21^{\prime}$ to $20^{\circ} 30^{\prime} \mathrm{N}$ latitude and $85^{\circ} 46^{\prime}$ to $85^{\circ} 57^{\prime}$ longitude and covers an area of about 147sq.km. (Fig.1).

The city is sandwiched between Kathajodi, a distributary of Mahanadi on the south and river Mahanadi itself on the north. The region is one of the most densely populated areas and no wonder, has witnessed a lot of urbanization and anthropogenic activity. The so called 'Urban Sprawl' of the region can be witnessed from the significant encroachment of the river beds along the banks of the two rivers where planned plots for new settlements can be visualized from satellite imagery. Because of the two rivers bordering the study area on three sides, extensive earth embankments can be seen along the periphery of the city. 


\section{METHODOLOGY}

The creation of the geospatial database for any region involves both primary and secondary sources of data. In the present case, primary source of data involved the establishment of ground control points (GCPs) for the pilot study area which were then used for geo-coding of all the collected maps and related attribute information along with the acquisition of positional information of various physical and cultural features. In this regard a preliminary reconnaissance survey of the study region was carried out using Survey of India (SOI) Toposheet number F45T15 with a scale of 1:50,000. For this, the assistance of some local people was also taken. The survey established possible site locations for the establishment of GCP. The tentative locations thus identified are primarily permanent and static in nature pertaining to various natural and manmade objects such as intersection of major roads, old monuments (fort) etc. The final selection of GCPs from possible site locations was based on the presence of the concerned features on the collected maps. Primary data collection involved extensive field visits and use of the technology of Global Positioning System (GPS).

Secondary sources of information involved the acquisition of geospatial maps and attribute data from various government and non-government agencies. The organizations which were visited for this purpose were Cuttack Municipal Corporation (CMC), Public Health Department (PHD), Public Work Department (PWD), Settlement Office, District Education Office, Cuttack Development Authority (CDA), District Information Office (DIO), Bharat Sanchar Nigam Limited (BSNL), office of the Superintendent of India Post, State Transport Authority Office, office of the Superintendent of Traffic Police, Chief District Medical Office (CDMO), Central Electricity Supply Unit (CESU), Airtel Communication, ORTEL Communication, Reliance Communication, Cuttack Malgodam Association, Chhatrabazar Association and Badambadi Bus Owner's Association. For the geospatial analysis and logic building the SOI Toposheet F45T15 was used as the base map. This toposheet was georeferencd in GIS environment with WGS84 World Geographic Coordinate System by $1^{\text {st }}$ order polynomial (Affine) transformation. For the sake of homogeneity, all the acquired and collected data were geo-referenced with the above coordinate system and transformation procedure. The spatial maps collected from the CMC was used for the demarcation of ward boundaries whereas, other secondary sources primarily furnished various attribute information of the city features and management.

All the above gathered information was then spatially analyzed to create various thematic layers of the study area (Fig. 2). Creation of thematic spatial features involved the process of manual digitization in GIS environment (Abel et al, 1995; Esperança and Samet, 1997; Hjaltason and Samet, 1995). . The digitized spatial objects were validated by ground-truthing as well as by visual interpretation of Digital
Globe Quick Bird image of Google Earth Web Map Service. The satellite image formed an integral part for the interpretation of various physiographic and geomorphic units of the study area in conjunction with detailed field survey.

\section{DISCUSSION}

The geospatial database created for the study area took into account the various physical and cultural features existing on the concerned landscape. As described earlier (Section II), the city is one of the oldest in the country and extensive urbanization is witnessed along all parts of the region. No wonder, cultural features dominate the study area with dense road network. The westernmost part which is being planned for new settlements somewhat shows semi urban environments with dense vegetation cover and paleochannels which are well recognised from satellite imagery. However, decentralized governance makes the governing authorities to divide spatial entities into smaller subdivisions for better management and implementation of schemes. In a like manner, the CMC has divided the city in to 59 wards for proper management and monitoring of social welfare schemes.

These imaginary political boundaries are used as the spatial boundaries by the concerned government, private and public agencies for planning purposes for which the line departments assume prime significance. However, effective planning of the city calls for accurate spatial information which has a common spatial referencing system. The lack of this standard spatial information brings in a lot of chaotic scenarios during the social welfare endeavours by the various line departments as well as the CMC authorities who also lack in coordination. This is exactly why, the secondary data acquired from various agencies displayed significant inconsistency when spatially interpolated to bring them to a common platform. Hence, for the removal of this erroneous information SOI toposheet in combination with the satellite imagery were used as the base map for spatial referencing system.

It is well established that the accuracy of geocoding of spatial information depended on the number of ground control points. Hence a significant number of GCPs i.e. a total of 309 were acquired from ground truthing and satellite image analysis for rubber sheet matching between the secondary data sheets and the base map (Fig. 2). 


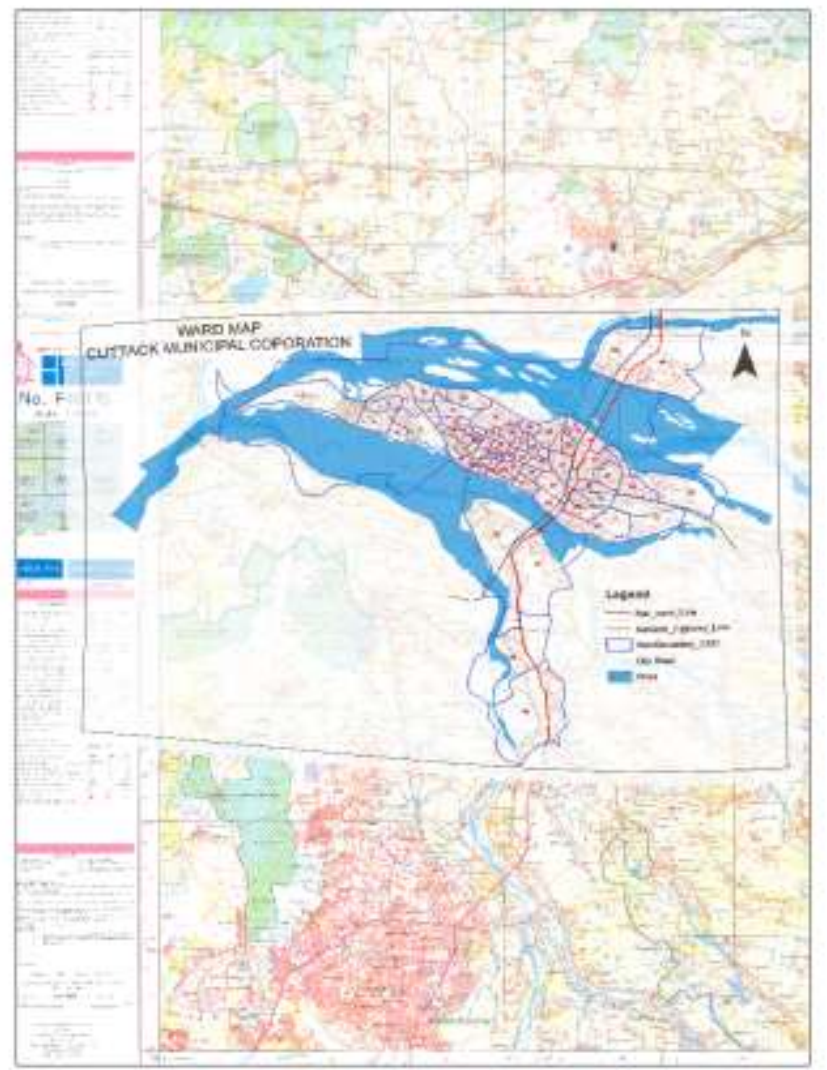

The root mean square error for this spatial transformation was kept within 0.5. This spatial matching of the secondary information also involved the personnel from the concerned agencies who are primarily engaged on ground implementation of the schemes. Once the spatial information was brought to a common referencing platform, overlay analysis with the acquired satellite imageries was carried out for validation purpose.

Fig-2: Rubber sheet matching of CMC ward map and SOI toposheets

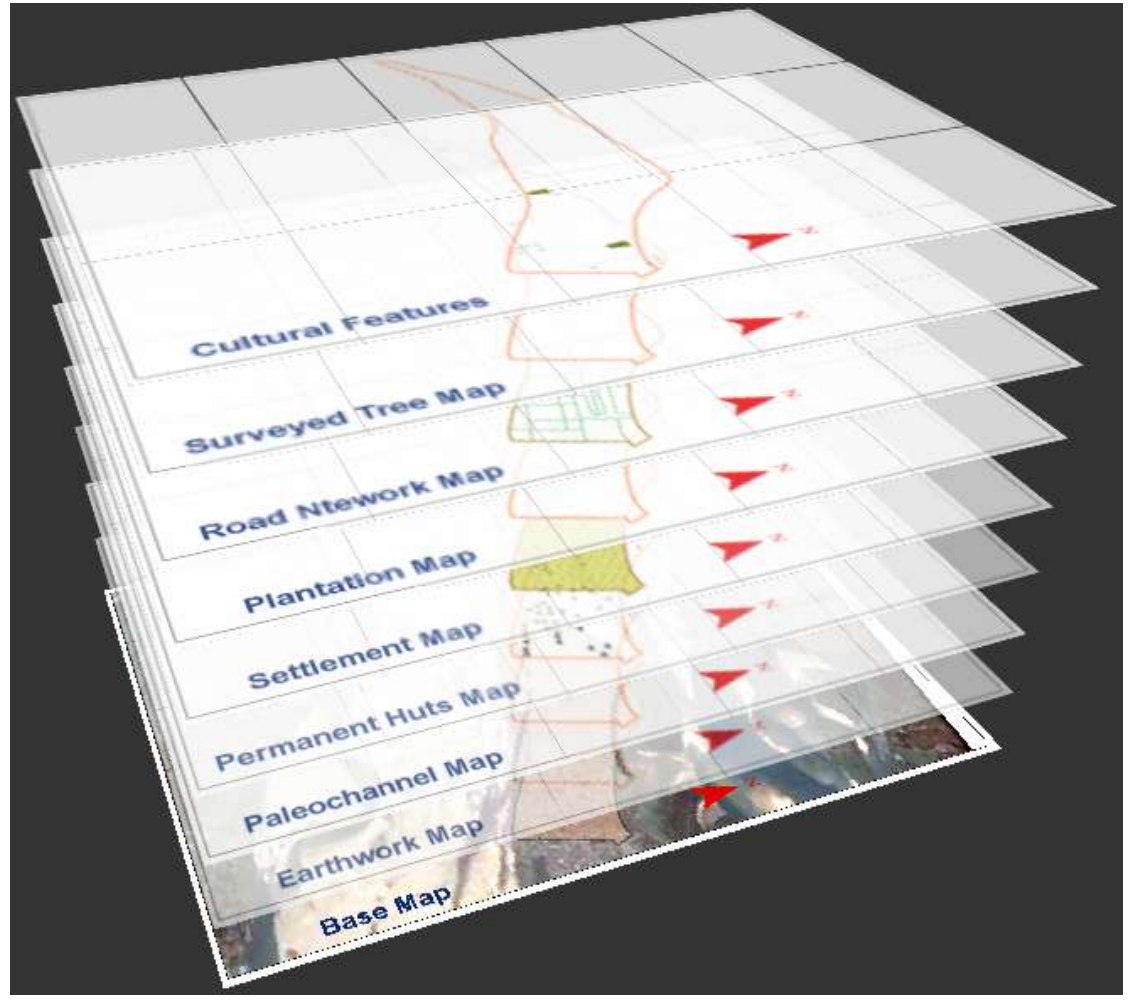

Fig-3. Extracted thematic layers of ward 3, CMC 
Keeping in mind the multi source nature of the acquired data, a world geographic datum WGS84 was used for geocoding of all the acquired spatial information to bring in consistency during analysis.

From the overlay analysis as well as visual interpretation various physical and cultural feature were digitized including road network, settlements, permanent huts, plantations, various manmade architectures, surveyed trees, paleochannels and earth embankments etc.. The identification and digitization of all these features also took into account ground truthing information and the GPS Locational information and formed the concerned thematic layers of the landscape (Fig. 3 ). These extracted features of the study area assume prime importance in decentralizing the planning of the urban activity. Overlay analysis of the features can be used by various line departments for their new endeavours as well as for the proper management of the existing infrastructure. Similarly futuristic development planning of the region can be accomplished by thorough site selection from GIS analysis. The biggest advantage of this spatial database is the common referencing of all the features with respect to a common base map which is accurate and unbiased. This has a greater impact on the coordination between different institutions. More often than not, it is the lack of proper coordination between various public departments that brings the chaotic nature of city urbanization. However, from the capability of periodic updation of spatial data, the biggest question of urban development i.e. 'where' can be answered. While the topographic maps for the wards (Fig. 4) gives an overall synoptic view of the region, the extracted feature layers from GIS analysis gives specific objective oriented solutions that can be utilized for human prosperity.

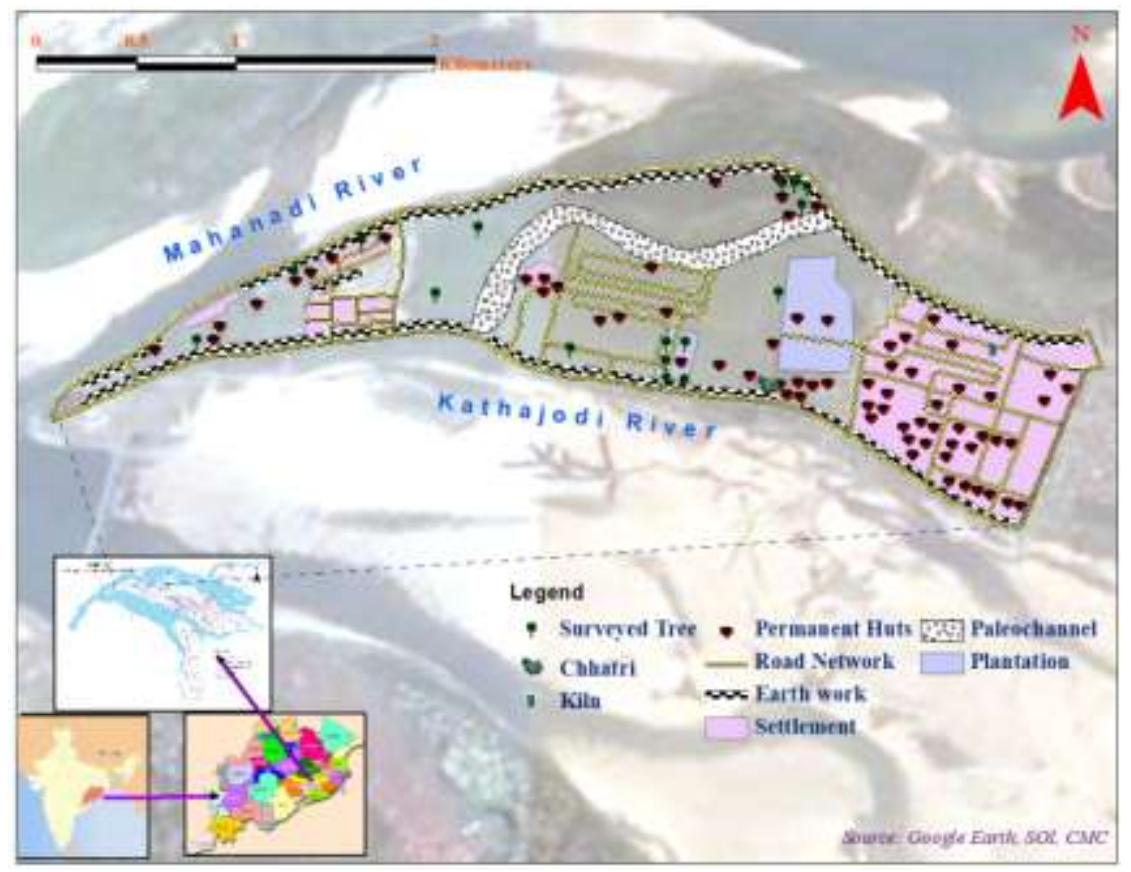

Fig- 4. Physical and cultural features of ward 3, CMC

\section{CONCLUSION}

Geospatial database creation assumes a significant position in the sustainable development of urban-local bodies. A case study has been carried out for the CMC, Odisha wherein spatial database for the area has been established to add to the different government, private and public entities working for human development. The work establishes the existence significant errors within the acquired secondary spatial information which lack in consistency. Elimination of these spatial errors has been carried out based on extensive ground truthing and satellites image analysis along with taking into account the knowledge of involved personnel of different organizations at ground level. Through the process of manual digitization and overlay analysis, the studies establishes various thematic layers of the $\mathrm{CMC}$ along with its spatial and attribute information which shows enormous potential towards greater coordination and integration between various line departments, planning agencies and public forums. However, the study is with respect to a single municipality area and extension of the research needs to be critically evaluated when applied to a larger spatial entity.

\section{ACKNOWLEDGEMENT}

The study is a part of the project awarded by DST, New Delhi. The authors sincerely thank DST for its financial support. They also wish to thank Prof. M.I. Hassan for his valuable comments. The authors also acknowledge the extended help of Mr. Nihar Ranjan Sahoo and Mr. Subrat Acharya at different stages of this study. 


\section{REFERENCES}

[1] ABDELMOTY, A.I., WILLIAMS, M.H, AND PATON, N.W. (1993), Deduction and Deductive Databases for Geographic Data Handling. Proc. 3rd Intl. Symposium on Large Spatial Databases, Singapore, 443-464.

[2] ABEL, D.J., OOI B.C., TAN, K.L, POWER, R., AND YU, J.X. (1995) Spatial Join Strategies in Distributed Spatial DBMS. Proc. 4th Intl. Symposium on Large Spatial Databases, 348-367.

[3] ABEL, D.J., SIRO-DBMS (1989): A Database Tool Kit for Geographical Information Systems. Intl. J. Of Geographical Information Systems 3, 103-116.

[4] BATINI, C., CERI, S. AND NAVATHE, S. B. (1992) Conceptual database design, an entity-relationship approach. Redwood City, Benjamin Cummings.

[5] BEDARD, Y. (1999) Principles of Spatial Database Analysis and Design, GIS: Principles, Techniques, Applications \& Management, Wiley, Vol. 2nd Ed., No. Chap. 29, p. 413-424.

[6] ELMASRI, R. AND NAVATHE, S .B. (1989) Fundamentals of Database Systems, CA, USA: Benjamin/Cummings Publishing.

[7] ESPERANÇA, C. AND SAMET, H. (1997) An overview of the SAND spatial database system, to appear in Communications of the ACM, http://www.cs.umd.edu/ hjs/pubs/sandprog.ps.gz.

[8] HARTMUT, G.R. AND FERNUNIVERSITÄT, H. P., Informatik IVD-58084 Hagen Germany gueting@fernuni-hagen.de

[9] HJALTASON, G. AND SAMET, H. (1995) Ranking in Spatial Databases in Advances in Spatial Databases $-4^{\text {th }}$ Symposium, SSD'95., Egenhofer J. R. and Herring J. R, Eds., Lecture Notes in Computer Science 951,SpringerVerlag, Berlin, 83-95. http://www.cs.umd.edu/ hjs/pubs/incnear.ps

[10] SHELDON, P. J. (1993) "Destination Information Systems", Annals of Tourism Research, Vol. 20, pp.633649. 